\title{
Karakteristik Berahi Kerbau Betina pada Berbagai Protokol Sinkronisasi di Kabupaten Kampar, Provinsi Riau
}

\section{(Estrus Characteristic of Female Buffalo on Various Synchronization Protocol in Kampar Regency, Riau Province)}

\author{
Yendraliza ${ }^{1}$, Handoko $\mathrm{J}^{1}$, Rodiallah $\mathrm{M}^{1}$, Arman $\mathrm{C}^{2}$ \\ ${ }^{I}$ Faculty of Agriculture and Animal Science, State Islamic University SUSKA Riau \\ Jl. HR Soebrantas Km 15 Panam, Pekanbaru 28293, Indonesia. \\ ${ }^{2}$ Faculty of Animal Science, Mataram University \\ Jl. Majapahit 62 Mataram, NTB 83125, Indonesia \\ lizafapet@gmail.com
}

\begin{abstract}
Identification of estrus behavior is important to determine the right time for mating. This study used 60 females buffalo which had given birth owned by farmer in the Tanjung villages, Taratak village and Salo village of Kampar regency. The synchronization protocol used PGF2 $\alpha$ - PGF2 $\alpha$, GnRH-PGF2 $\alpha$ and without hormone synchronization protocol. The study result showed that there were difference $(\mathrm{P}<0.05)$ among treatments on the intensity of estrus, percentages of estrus $(100 \%)$, onset of estrus $(30,80 \mathrm{~h}$ to $2,5 \mathrm{~h})$, and duration of estrus (18,6 h to $6,5 \mathrm{~h})$. In conclusion, synchronization protocol on females buffalo in Kampar Regency using combinations of GnRH and PGF2 $\alpha$ in post partum period make higher estrus intensity, faster estrus and longer estrus duration.
\end{abstract}

Key Words: Synchronization, Female Buffalo, Post Partum, PGF2 $\alpha$

\begin{abstract}
ABSTRAK
Identifikasi perilaku estrus penting dalam menentukan waktu yang tepat untuk kawin. Penelitian ini menggunakan 60 ekor kerbau betina yang pernah beranak berasal dari peternakan masyarakat di Desa Tanjung, Desa Taratak dan Desa Salo, Kabupaten Kampar. Perlakuan protokol sinkronisasi estrus yang digunakan adalah PGF2 $\alpha$ - PGF2 $\alpha$, GnRH-PGF2 $\alpha$ dan tanpa protokol sinkronisasi hormon. Parameter yang diamati adalah intensitas estrus, persentase estrus, onset estrus dan lama estrus. Hasil studi menunjukkan bahwa ada perbedaan $(\mathrm{P}<0,05)$ pada intensitas estrus tinggi, persentase estrus (100\%), kecepatan munculnya estrus (30,80 jam hingga 2,5 jam), dan lama estrus (18,6 jam hingga 6,5 jam). Dapat disimpulkan bahwa protokol sinkronisasi kombinasi GnRH dan PGF2 $\alpha$ pada kerbau betina di Kabupaten Kampar periode post-partum menghasilkan intensitas estrus yang tinggi, munculnya estrus lebih cepat dan durasi estrus lebih lama.
\end{abstract}

Kata Kunci: Sinkronisasi, Kerbau Betina, Pos Partum, PGF2 $\alpha$

\section{PENDAHULUAN}

Kerbau memainkan peranan penting dalam perekonomian di Kabupaten Kampar. Lima puluh persen produksi daging di Kabupaten Kampar berasal dari ternak kerbau (Disnak Provinsi Riau 2010). Sumber yang sama menyatakan bahwa total populasi ternak kerbau sebanyak 21,342 ekor atau 44,64\% dari total jumlah keseluruhan populasi kerbau Provinsi Riau. Produksi daging kerbau di Kabupaten Kampar adalah 40,89\% dari total produksi daging kerbau secara keseluruhan di Provinsi Riau tahun 2010. Namun jumlah populasi ini tidak mengalami peningkatan dari tahun 2004 (21.274 ekor) dan tahun 2010 
(21.703 ekor). Menurut Toelihere (1981), rendahnya peningkatan populasi ini disebabkan oleh kurangnya pengetahuan dan perhatian peternak terhadap aspek-aspek reproduksi.

Proses reproduksi pada ternak kerbau sangat lambat ditandai dengan keterlambatan pubertas. Hal ini terlihat dari umur melahirkan pertama kali pada ternak kerbau adalah 3,5 $\pm 0,6$ tahun (Yendraliza et al. 2010). Beberapa faktor penyebabnya adalah lingkungan, gizi dan manajemen yang dilakukan oleh peternak (Nanda et al. 2003). Kendala utama yang dirasakan menghambat pelaksanaan perkawinan pada kerbau adalah sulitnya deteksi berahi karena gejala berahi umumnya tidak jelas atau berahi tenang (silent heat) (Putro 1991). Nanda et al. (2003) menyatakan bahwa sulitnya deteksi berahi pada kerbau disebabkan karena peternak masih melakukan sistem pemeliharaan yang ekstensif dan kebiasaan ternak kerbau yang suka berkubang. Penggunaan beberapa protokol sinkronisasi telah mampu memunculkan estrus pada sapi dan beberapa kerbau di luar negeri.

Deteksi estrus meliputi karakteristik, persentase dan kecepatan munculnya estrus menggunakan hormon sikronisasi sudah dilakukan pada kerbau-kerbau di luar negeri. Seperti kerbau Mediterania (De Araujo et al. 2002), kerbau Mesir (Bartolomeo et al. 2002), dan kerbau Mediterania (Neglia et al. 2003). Deteksi estrus secara natural belum pernah dilakukan khususnya untuk kerbau lokal. Penelitian ini bertujuan meneliti tingkah laku pada saat estrus sangat dibutuhkan untuk mendeteksi estrus karena ketepatan deteksi estrus sangat dibutuhkan untuk melakukan kawin tepat waktu.

\section{MATERI DAN METODE}

Penelitian menggunakan 60 ekor kerbau betina yang berasal dari peternakan rakyat di Desa Salo, Desa Taratak dan Desa Tanjung. Ternak kerbau betina dibagi dalam 3 kelompok setelah dilakukan palpasi rektal untuk menentukan kebuntingan. Penelitian ini menggunakan rancangan acak kelompok (RAK) dengan tiga perlakuan. Masing-masing perlakuan terdiri dari 20 ekor ternak kerbau betina yang menjadi ulangan dengan berat badan $225-325 \mathrm{~kg}$ dan sudah pernah melahirkan. Kelompok pertama: diinjeksikan $5 \mathrm{ml}$ PGF2 $\alpha$ pada hari pertama penelitian, sebelas hari kemudian diinjeksikan $5 \mathrm{ml}$ PGF2 $\alpha$. Dua hari setelah injeksi PGF2 $\alpha$ ke-2 dilakukan pengamatan. Kelompok kedua: diinjeksikan hormon $3 \mathrm{ml} \mathrm{GnRH}$ pada hari pertama penelitian, tujuh hari berikutnya di injeksikan 2,5 ml PGF2 $\alpha$. Kelompok ketiga adalah tanpa perlakuan hormon.

Ternak penelitian ditempatkan di kandang koloni milik Balitbang Kampar pada malam hari dan dilepaskan pada pagi hari di lapangan rumput yang ada di sekitar kandang. Kerbau betina diseleksi berdasarkan kesehatan reproduksi, tidak mengalami gangguan saluran reproduksi, tidak sedang bunting dan tidak memiliki corpus luteum. Kerbau-kerbau tersebut mempunyai aktivitas ovarium dan kondisi uterus yang normal berdasarkan hasil diagnosa melalui palpasi rektal yang dilakukan oleh dokter hewan dan petugas pemeriksa kebuntingan dari Dinas Peternakan Kabupaten Kampar. Pengamatan estrus dilakukan selama 21 hari selama periode estrus.

Peubah yang diukur dalam penelitian ini adalah: (a) Intensitas estrus, yaitu: tingkat aktivitas tingkah laku estrus yang muncul setelah penyuntikan hormon dilakukan yang dapat dibedakan atas: 1. Intensitas tinggi: apabila ternak kerbau memperlihatkan semua gejala-gejala estrus, seperti vulva membengkak, merah dan hangat dan diam bila dinaiki. 2. Intensitas sedang: apabila ternak kerbau memperlihatkan semua gejala-gejala estrus kecuali gejala diam bila dinaiki. 3. Intensitas rendah: apabila ternak kerbau hanya memperlihatkan sebagian kecil gejala estrus; (b) Kecepatan munculnya estrus, yaitu jarak antara penyuntikan PGF2 $\alpha$ sampai munculnya estrus yang ditandai dengan tampaknya lendir yang nyata (jam); (c) Lama estrus, yaitu interval waktu antara penampakan estrus pertama kali dengan berakhirnya estrus yang ditandai dengan tidak adanya lendir 
menggelantung di bibir vulva (jam); (d) Persentase estrus. Keragaman semua data yang dikumpulkan dianalisa dengan rancangan acak kelompok (RAK) (Steel \& Torrie 1991), perbedaan nilai rata-rata diuji dengan dengan uji Duncan.

\section{HASIL DAN PEMBAHASAN}

Penggunaan protokol sinkronisasi yang berbeda pada kerbau betina yang sudah beranak memberikan perbedaan yang nyata pada intensitas estrus, kecepatan munculnya estrus, lamanya estrus dan persentase estrus jika dibandingkan dengan kerbau betina yang tidak mendapatkan hormon sinkronisasi.

Tabel 1. Intensitas estrus, kecepatan munculnya estrus, lamanya estrus dan presentase estrus kerbau betina

\begin{tabular}{lcccc}
\hline \hline $\begin{array}{l}\text { Penggunaan hormon } \\
\text { sinkronisasi }\end{array}$ & $\begin{array}{c}\text { Intensitas } \\
\text { estrus }\end{array}$ & $\begin{array}{c}\text { Kecepatan muncul } \\
\text { estrus (jam) }\end{array}$ & $\begin{array}{c}\text { Lama estrus } \\
\text { (jam) }\end{array}$ & $\begin{array}{c}\text { Persentase } \\
\text { estrus }(\%)\end{array}$ \\
\hline PGF2 $\alpha$-PGF2 $\alpha$ & Sedang & $39,05^{\mathrm{a}} \pm 10,4$ & $29,9^{\mathrm{a}} \pm 2,16$ & 100 \\
GnRH-PGF2 $\alpha$ & Tinggi & $30,80^{\mathrm{b}} \pm 2,5$ & $18,6^{\mathrm{b}} \pm 6,5$ & 100 \\
Tanpa hormon & Rendah & 0 & $15,80^{\mathrm{c}} \pm 2,5$ & 70 \\
\hline
\end{tabular}

Superskrip yang berbeda pada kolom yang sama menunjukkan perbedaan sangat nyata $(\mathrm{P}<0,01)$

Berbedanya intensitas estrus, kecepatan munculnya estrus dan lamanya estrus serta persentase estrus pada kerbau betina yang mendapat hormon sinkronisasi yang berbeda kemungkinan disebabkan oleh jenis protokol yang digunakan juga berbeda. Perbedaan ini juga kemungkinan disebabkan oleh ukuran tubuh ternak juga berbeda. Pendapat ini sejalan dengan Dewi et al. (2011), bahwa kondisi tubuh ternak mempengaruhi kinerja dari protokol sinkronisasi. Jainudeen \& Hafez (1987) menyatakan bahwa aktivitas ovarium dipengaruhi oleh faktor fisiologis dan kondisi tubuh ternak. Selain kondisi ternak dan kecukupan pakan, faktor stage/fase siklus estrus (kondisi folikuler atau luteal ovarium) dari ternak akseptor pada saat pemberian hormon juga sangat mempengaruhi efisiensi dari protokol sinkronisasi estrus. Perbedaan kondisi folikuler atau luteal ini akan memberikan variasi waktu terjadinya estrus sehingga PGF2 $\alpha$ akan efisien menginduksi luteolisis (De Rensis \& Lopez-Gatius 2007). Selanjutnya diketahui bahwa keberhasilan sinkronisasi estrus pada ternak harus mempunyai body condition score (BCS) 5 atau lebih.

Perbedaan intensitas estrus, kecepatan estrus, lama estrus dan persentase estrus pada kerbau yang sudah melahirkan ini sejalan dengan hasil penelitian Saili et al. (2011) yang menyatakan bahwa respon individu akan mempengaruhi kinerja protokol sinkronisasi terhadap organ targetnya. Penggunaan kombinasi hormon GnRH dengan PGF2 $\alpha$ lebih baik pada kerbau betina yang sudah beranak dibandingkan dengan penggunaan hormon PGF $2 \alpha$ - PGF2 $\alpha$ dan yang tanpa menggunakan hormon sinkronisasi. Metwelly \& El-Bawab (1999) menyatakan bahwa penggunaan GnRH pada kerbau yang sudah melahirkan akan mempengaruhi pembentukan kembali siklik ovarium sehingga penambahan PGF2 $\alpha$ setelah itu akan mampu melisis corpus luteum dengan segera dan menurunkan konsentrasi hormon progesteron (Gordon et al. 1996). Hal ini kemungkinan sama dengan laporan Rhodes et al. (2003) bahwa penggunaan GnRH dengan PGF2 $\alpha$ akan memperjelas estrus pada kerbau. Ditambahkan oleh Paul \& Prakash (2005) bahwa GnRH akan memacu pertumbuhan folikel sehingga memperbanyak corpus luteum yang terbentuk.

Rendahnya karakteristik estrus pada kerbau yang tidak menggunakan hormon sinkronisasi kemungkinan disebabkan rendahnya hormon estrogen yang dihasilkan oleh 
folikel yang berfungsi untuk memunculkan ciri-ciri estrus lebih sedikit jika dibandingkan dengan hormon estrogen yang dihasilkan oleh kerbau yang mendapatkan hormon PGF2 $\alpha$ dan GnRH (Hafez 2000). Hal ini terlihat berbeda pada tingkah laku estrus kerbau betina yang diberi hormon dengan kerbau betina yang tidak diberi hormon (Tabel 2). Rendahnya kadar hormon ini kemungkinan disebabkan karena kecilnya jumlah folikel yang dipunyai oleh kerbau (Perera 2010) sehingga dengan penambahan hormon GnRH akan memacu pertumbuhan folikel (Noakes et al. 2001).

Tabel 2. Perubahan tingkah laku, vulva dan sekresi lendir kerbau betina di Kabupaten Kampar

\begin{tabular}{lccc}
\hline \hline $\begin{array}{l}\text { Pengggunaan hormon } \\
\text { sinkronisasi }\end{array}$ & $\begin{array}{c}\text { Perubahan } \\
\text { tingkah laku }\end{array}$ & Sekresi lendir & Perubahan vulva \\
\hline PGF $_{2 \alpha}-\mathrm{PGF}_{2 \alpha}$ & Sedang & terlihat & abuh, abang, angat \\
GnRH-PGF $_{2 \alpha}$ & Tinggi & Terlihat sangat jelas & abuh, abang, angat \\
Tanpa hormon & Rendah & Terlihat tapi samar-samar & abuh, abang, angat \\
\hline
\end{tabular}

Besarnya persentase perubahan tingkah laku ternak kerbau yang diberi hormon GnRH - PGF2 $\alpha$ daripada ternak kerbau yang tidak mendapat penambahan hormon sinkronisasi kemungkinan disebabkan oleh banyaknya folikel yang terbentuk akibat penambahan GnRH (Barile 2005). Putro (1991) menyatakan bahwa penambahan GnRH akan meningkatkan jumlah folikel pada ternak kerbau karena jumlah folikel pada ternak kerbau hanya separuh dari jumlah folikel pada ternak sapi. Menurut Toelihere (1981) intensitas berahi pada kerbau dan sapi dinilai berdasarkan pada perubahan vulva yaitu berwarna kemerahan, pembengkakan dan panas, lendir tembus pandang keluar dari vulva. Perubahan tingkah laku yaitu melenguh, gelisah dan menaiki sesama betina (homoseks) dan ketegangan uterus.Hasil pengamatan Arya \& Madan (2001), Jainudeen (1986) dan Toelihere (1981) menunjukkan bahwa gejala berahi ditandai oleh keluarnya lendir yang bening dari vulva. Pada vulva bengkak, gelisah, saling menaiki, mencari pejantan, nafsu makan berkurang, mengangkat ekor bila vulva diraba, sering kencing dan selalu melenguh.

\section{KESIMPULAN}

Penggunaan protokol sinkronisasi GnRH-PGF2 $\alpha$ pada kerbau betina yang sudah beranak menghasilkan intensitas estrus yang tinggi, cepatnya kemunculan estrus pada durasi estrus yang lebih lama jika dibandingkan dengan penggunaan PGF2 $\alpha-P G F 2 \alpha$ dan tanpa menggunakan preparat hormon sinkronisasi. Untuk memperjelas estrus pada ternak kerbau yang sudah beranak dapat menggunakan hormon GnRH pada hari ke-1 dan PGF2 $\alpha$ pada hari ke-7 setelah GnRH.

\section{UCAPAN TERIMA KASIH}

Terima kasih disampaikan kepada peternak kerbau telah berpartisipasi dalam penelitian ini sehingga didapatkan sejumlah ternak resepien. Ucapan terimakasih disampaikan kepada Rektor UIN Suska Riau melalui Direktur Lembaga Penelitian UIN Suska Riau yang telah mensponsori sebagian penelitian ini. Selanjutnya terimakasih disampaikan kepada Balitbang Kampar melalui Bidang Teknologi yang telah mensponsori penelitian ini hingga selesai. 


\section{DAFTAR PUSTAKA}

Arya JS, Madan ML. 2001. Post partum gonodotropin insukled and weaned buffaloes. Ind Vet J. 78:405-409.

Barile VL. 2005. Reproductive efficiency in female buffalo. In: Buffalo production and research. Borghese A, editor. REU Tech. series 67. Rome (Italy): FAO. p. 77-107.

Bartolomeu CC, Del Rei AJM, Madureira EH, Souza AJ, Silva AO, Baruselli PS. 2002. Timed insemination using synchronization of ovulation in buffaloes using CIDR-B, CRESTAR and Ovsynch. Anim Breed Abstr. 70:332.

De Araujo Berber RC, Madureira EH, Baruselli PS. 2002. Comparison of two Ovsynch protocols (GnRH versus LH) for fixed-timed insemination in buffalo (Bubalus bubalis). Theriogenology. 57:1421-30.

De Rensis F, López-Gatius F. 2007. Protocols for synchronizing estrus and ovulation in buffalo (Bubalus bubalis): A review. 67, Therionology. 2:209-216.

Dewi RR, Wahyuningsih, Widayati DT. 2011. Respon estrus pada kambing peranakan Ettawa dengan Body condition score 2 dan 3 terhadap kombinasi Implant controlled internal drug release jangka pendek dengan injeksi prostaglandin $\mathrm{f} 2$ alpha. J Kedokt Hewan UGM. 5:11-16.

Disnak Provinsi Riau. 2010. Statistik Peternakan Provinsi Riau. Pekanbaru (Indonesia): Dinas Peternakan dan Kesehatan Hewan Provinsi Riau.

Gordon PJ, Peters AR, Ward SJ, Warren MJ. 1996. The use of prostaglandin in combination with a GnRH agonist in controlling the timing of ovulation in dairy cows. Reproduction. 24:164-168.

Hafez ES. 2000. Reproduction in farm animals. Philadelpia (USA): Lea and Febiger.

Jainudeen MR, Hafez ESE. (1987). Cattle and water buffalo. In: Hafez ESE, editor. Reproduction in farm animals. 5th. ed. Philadelpia (USA): Lea and Febiger.

Jaenudeen. 1986, Reproduction in water buffalo, In: Morrow DA, editor. Current therapy in theriogenology 2. Philadelpia (USA): W.B. Saunderey Co.

Metwelly KK, El-Bawab IE. 1999. A study to improve the reproductive efficiency in postpartum cattle and buffaloes. Assiut Vet Med J. 42:83.

Nanda AS, Brar PS, Prabhakar S. 2003. Eahancing reproductive performance in dairy buffalo: Mayor Coastain And Achieverme In: Proceeding of the Sixth International Syaposium On Reproduction In Domestic Ruminant's. vol 61. crifft Scotland VLC. p. 27-36.

Neglia G, Gasparrini B, Palo RD, Rosa CD, Zicarelli L, Campanile G. 2003. Comparison of pregnany rates with two oestrus synchronization protocols in Italian Mediterranean buffalo cows. Theriogenology. 60:125-33.

Noakes DE, Parkinson TJ, England GCW. 2001. Arthur's veterinary reproduction and obstetrics. $8^{\text {th }}$ ed. London (UK): Baillier Tindall.

Paul V, Prakash BS. 2005. Efficacy of the ousyeach protocol for synekronizatzon of ouulation and fixed time artificial inseminator in Murrah Buffaloes (Bubalis bubalus). Theriogenology 64:1049-1060.

Perera BMAO. 2010. Reprodctive cycles of buffalo. J Anim Reprod Sci. 121:189-300.

Putro PP. 1991. Sinkronisasi berahi pada kerbau: Aktivitas ovarium dan profil progesteron darah. Bul FKH UGM XIV.

Rhodes FMS, McDougall SR, Burke GA, Verkerk, MacMillan KL. 2003. Invited review. Treatment of cows with on extended postpartum anoestrus interval. J Dairy Sci. 86:1876-1894.

Saili T, Bain A, Aku AS, Rusdin M, Aka R. 2011. Sinkronisasi estrus melalui manipulasi hormon agen luteolitik untuk meningkatkan efisiensi reproduksi sapi Bali dan Peranakan Ongole di Sulawesi Tenggara. Agriplus. 21:50-54. 
Steel RGD, Torrie JH. 1991. Principles and procedures of statistics. New York (USA): McGrawHill Book Co. Inc.

Toelihere MR. 1981. Fisiologi reproduksi pada ternak. Bandung (Indonesia): Penerbit Angkasa.

Yendraliza, Zesfin BP, Udin Z, Jaswandi. 2010. Karakteristik reproduksi kerbau lumpur (swamp buffalo) betina di Kabupaten Kampar. Dalam: Prasetyo LH, Natalia L, Iskandar S, Puastuti P, Herawati T, Nurhayati, Anggraeni A, Damayanti R, Dharmayanti NLPI, Estuningsih SE, penyunting. Teknologi peternakan dan veteriner ramah lingkungan dalam mendukung program swasembada daging dan peningkatan ketahanan pangan. Prosiding Seminar Nasional Teknologi Peternakan dan Veteriner. Bogor, 3-4 Agustus 2010. Bogor (Indonesia): Puslitbangnak. hlm.

\section{DISKUSI}

\section{Pertanyaan}

1. Apakah waktu pemberian perlakuan GnRH dan PGF2 $\alpha$ dilakukan segera setelah melahirkan atau bagaimana?

2. Apakah ada dampak negatif penambahan hormon terutama dalam jumlah yang banyak?

3. Apakah sudah ada lanjutan berupa tindakan langsung di IB setelah perlakuan?

4. Apakah dari segi biaya, kombinasi GnRH dan PGF2 $\alpha$ bisa terjangkau terutama oleh peternak?

\section{Jawaban}

1. Secara teori, pada dasarnya mekanisme kerbau kembali berahi terjadi setelah 2 s.d 3 bulan melahirkan, waktu terbaik biasanya 3-6 bulan kelahiran. Tetapi, penelitian ini menggunakan ternak milik warga masyarakat di sekitar lokasi penelitian yang dikumpulkan di satu tempat yaitu kandang koloni milik Balitbang Kampar, sehingga masa kelahiran hingga perlakuan dari setiap kerbau percobaan berbeda-beda.

2. Pada dasarnya hormon di dalam tubuh diproduksi dalam jumlah sedikit karena fungsinya sebagai perangsang terhadap sel target untuk melakukan suatu tindakan. Pemberian hormon dalam jumlah yang banyak kemungkinan tidak memiliki efek atau justru akan memberi efek negatif terutama pada hormon reproduksi. Pemberian hormon reproduksi dalam jumlah yang banyak dikhawatirkan bisa menyebabkan kelainan reproduksi seperti terjadinya kasus nimphomania pada ternak. Akan tetapi, penggunaan hormon pada penelitian ini sudah mengikuti standar jumlah perlakuan dan juga mengingat produksi folikel pada ternak kerbau adalah setengah dari kemampuan produksi folikel pada ternak sapi dan hal ini juga yang menyebabkan kerbau cenderung mengalami berahi tenang.

3. Penelitian ini bertujuan untuk melihat tingkat estrus pada ternak kerbau percobaan dan belum mencapai perlakuan IB. Menurut saya, ide cemerlang jika dilanjutkan dengan perlakuan IB dan waktu yang tepat untuk pelaksanaan IB tersebut.

4. Penggunaan kombinasi GnRH dan PGF2 $\alpha$ ini masih pada taraf penelitian. Jika kita melihat dari segi biaya memang akan mengeluarkan biaya yang cukup mahal jika di terapkan di lapangan mengingat kemampuan peternak dan kebiasaan peternak saat ini yang masih bersifat tradisional. 